5. Jain A, Reyes J, Kashyap R, et al. Liver transplantation under tacrolimus in infants, children, adults, and seniors: long-term results, survival, and adverse events in 1000 consecutive patients. Transplant Proc 1998; 30(4): 1403.

6. Jain A, Reyes J, Kashyap R, et al. What have we learned about primary liver transplantation under tacrolimus immunosuppression? Long-term follow-up of the first 1000 patients. Ann Surg 1999; 230(3): 441.

7. Mazariegos GV, Reyes J, Marino I, Flynn B, Fung JJ, Starzl TE. Risks and benefits of weaning immunosuppression in liver transplant recipients: long-term follow-up. Transplant Proc 1997; 29(1-2): 1174.

8. Stegall MD, Wachs ME, Everson G, et al. Prednisone withdrawal 14 days after liver transplantation with mycophenolate: a prospective trial of cyclosporine and tacrolimus. Transplantation 1997; 64(12): 1755.

9. Gomez R, Moreno E, Colina F, et al. Steroid withdrawal is safe and beneficial in stable cyclosporine-treated liver transplant patients. J Hepatol 1998; 28(1): 150.

10. Everson GT, Trouillot T, Wachs M, et al. Early steroid withdrawal in liver transplantation is safe and beneficial. Liver Transpl Surg 1999; 5(4 Suppl 1): S48.

11. Jain AB, Todo S, Fung JJ, et al. Correlation of rejection episodes with FK 506 dosage, FK 506 level, and steroids following primary orthotopic liver transplant. Transplant Proc 1991; 23(6): 3023.

12. Todo S, Fung JJ, Demetris AJ, Jain A, Venkataramanan R, Starzl TE. Early trials with FK 506 as primary treatment in liver transplantation. Transplant Proc 1990; 22(1): 13.

13. Tisone G, Angelico M, Palmieri G, et al. Immunosuppression without prednisone after liver transplantation is safe and associated with nor- mal early graft function: preliminary results of a randomized study. Transpl Int 1998; 11 (Suppl 1): S267.

14. Padbury RT, Gunson BK, Dousset B, et al. Steroid withdrawal from long-term immunosuppression in liver allograft recipients. Transplantation $1993 ; 55(4): 789$.

15. Punch JD, Shieck VL, Campbell DA, Bromberg JS, Turcotte JG, Merion RM. Corticosteroid withdrawal after liver transplantation. Surgery 1995; 118(4): 783.

16. Ramirez CB, Sebayel MI, Kizilisik T. Early steroid withdrawal after liver transplantation. Transplant Proc 1998; 30(7): 3182

17. McDiarmid SV, Farmer DA, Goldstein LI, et al. A randomized prospective trial of steroid withdrawal after liver transplantation. Transplantation 1995; 60(12): 1443.

18. DeCarlis L, Belli LS, Rondinara GF, et al. Early steroid withdrawal in liver transplant patients: final report of a prospective randomized trial. Transplant Proc 1997; 29(1-2): 539.

19. Mazariegos GV, Reyes J, Marino IR, et al. Weaning of immunosuppression in liver transplant recipients. Transplantation 1997; 63(2): 243.

20. Starzl TE, Demetris AJ, Murase N, Thomson AW, Trucco M, Ricordi C. Donor cell chimerism permitted by immunosuppressive drugs: a new view of organ transplantation. Trends Pharmacol Sci 1993; 14(5): 217.

21. McMaster P, Gunson B, Min X, Afonso R, Bastos J. Liver transplantation: changing goals in immunosuppression. Transplant Proc 1998; 30(5): 1819

Received 5 June 2000.

Accepted 11 September 2000.

\title{
IMPACT OF DONOR-SPECIFIC ANTIBODIES ON CHRONIC REJECTION OCCURRENCE AND GRAFT LOSS IN RENAL TRANSPLANTATION: POSTTRANSPLANT ANALYSIS USING FLOW CYTOMETRIC TECHNIQUES ${ }^{1}$
}

\author{
Antonina Piazza, ${ }^{2}$ Elvira Poggi,${ }^{3}$ Laura Borrelli, ${ }^{3}$ Simona Servetti,${ }^{3}$ Palmina I. Monaco, ${ }^{2}$ \\ Oreste Buonomo, ${ }^{3}$ Maurizio Valeri,${ }^{3}$ Nicola Torlone, ${ }^{3}$ Domenico Adorno, ${ }^{2,4}$ And
}

CARLO U. CASCIANI ${ }^{3}$

Consiglio Nazionale delle Ricerche, Institute of Tissue Typing, Unit of Rome; Clinical Surgery, "Tor Vergata” University of Rome, Italy

Background. Improvements in immunosuppressive therapy have greatly reduced acute rejection (ARj) episodes, ensuring better short-term graft outcome, but have not modified long-term survival in renal

1 This work was supported in part by C.N.R. Special Project "Biotechnology."

2 "Consiglio Nazionale delle Ricerche," Institute of Tissue Typing, Unit of Rome.

${ }^{3}$ Clinical Surgery, "Tor Vergata" University of Rome.

4 Address correspondence to: Domenico Adorno, Istituto CNR di Tipizzazione Tissutale e Problemi della Dialisi - Sezione di Roma, c/o Osp. S. Eugenio, Piazzale Dell'Umanesimo 10, 00144 Rome, Italy. E-mail: coortrap@uniroma2.it. transplantation. It is now well accepted that chronic rejection (CRj) can be determined by both immune and/or nonimmune mechanisms. The aim of this study was to evaluate the importance of the posttransplant humoral immune response towards mismatched HLA graft antigens in CRj occurrence and graft outcome.

Methods. Serum samples from 120 nonpresensitized renal transplant recipients were prospectively screened for 1 year after surgery by means of flow cytometry cross-match (FCXM) and FlowPRA beads (microbeads coated with purified HLA class I and class II antigens) assays. All transplants were followed-up for 2 years or until graft removal.

Results. FCXM monitoring identified donor-specific 
antibodies (DS-Abs) in $29(24.2 \%)$ of 120 transplanted patients. Correlation with clinical data highlighted a higher incidence of ARj in DS-Abs-positive patients compared to negative patients $(62 \%$ vs. $13 \%$, $P<0.00001)$. Furthermore, graft failure occurred more frequently among FCXM-positive patients than among negative patients $(34 \%$ vs. $1 \%, P<0.00001)$. The deleterious effect of DS-Abs on graft function was confirmed by serum creatinine levels 2 years after transplantation. These were in fact higher in subjects producing DS-Abs than in subjects with only ARj (mean creatinine: $2.5 \pm 1.3 \mathrm{mg} / \mathrm{dL}$ vs.1.7 $\pm 0.5 \mathrm{mg} / \mathrm{dL}, P=0.04)$. FlowPRA analysis of DS-Ab HLA specificity highlighted the presence of anti-HLA class I antibodies in $85 \%$ of FCXM-positive patients, who also presented with a higher incidence of HLA-B mismatches than FCXMnegative patients $(1.23 \pm 0.66$ vs. $0.92 \pm 0.59, P=0.02)$.

Conclusions. Flow cytometric techniques are precious tools for investigating the activation of the humoral response against HLA antigens of the graft in renal transplantation. DS-Abs production has a worse impact on organ function and survival than ARj episodes. These findings represent further proof of the threat posed by DS-Abs on long-term graft function and draw attention to the need for a specific immunosuppressive therapy aimed at counteracting the different kinds of immune activation toward graft.

The clinical use of cyclosporine in renal transplantation has improved short-term allograft survival (1) but has not produced similar results for long-term survival (2). Several studies have shown that the occurrence of early acute rejection (ARj) episodes and the appearance of donor-specific antibodies (DS-Abs) are the most important risk factors for the development of chronic graft failure (3-5). Recent studies have emphasized that the production of cytotoxic DS-Abs constitutes a negative prognostic factor for 1-year graft survival.

As far as the methodology to reveal the presence of alloantibodies is concerned, flow cytometry cross-match (FCXM) has shown to be more sensitive than complement-dependent lymphocytotoxicity (CDC) (6-8). The higher sensitivity of FCXM is due to its ability to identify complement-fixing and nonfixing antibodies and to simultaneously define the class of the detected immunoglobulin (IgG and/or IgM) and the different types of target cells ( $\mathrm{T}$ and/or B lymphocytes) (9). More recent is the FlowPRA screening test, a cytometric technique that uses microbeads coated with purified HLA antigens and allows the characterization of anti-HLA class I or II specificity (10).

Plenty of data are available concerning the clinical usefulness of flow cytometry cross-matching before renal transplantation. Several studies have shown that a positive FCXM before transplantation leads to a higher incidence of rejection episodes in primary renal transplantation and early graft loss in re-graft recipients (11-14). There is, on the other hand, limited information concerning the importance of posttransplant FCXM in monitoring donor-specific humoral immune response (15-17) and predicting the occurrence of chronic graft failure (18-19).

This study was aimed at characterizing posttransplant humoral immune response against mismatched HLA antigens of the graft to investigate the clinical relevance of such DS-Abs and evaluate the role of these alloantibodies in chronic rejection $(\mathrm{CRj})$ occurrence and renal graft survival. For this purpose, 120 cadaveric renal-transplanted patients were prospectively monitored with FCXM during the first year after transplantation.

\section{MATERIALS AND METHODS}

Patient population. Among the patients who underwent cadaveric renal transplantation at the Transplant Unit of Clinical Surgery, Tor Vergata University of Rome, between the years 1992-1997, only 120, who were negative for the presence of preformed antibodies against donor cells using both CDC-XM and FCXM and whose donor lymphocytes were available, were enrolled in the study. All but four patients had received kidney transplantation for the first time. Organs were assigned according to the best donor-recipient HLA compatibility; matching priority was HLA-DR, HLA-B, and HLA-A. Pretransplant patient characteristics are shown in Table 1.

Immunosuppression protocol. All patients received a triple-therapy regimen that consisted of cyclosporine/prednisone/azathioprine (Aza) or mycophenolate mofetil (MMF). Oral cyclosporine was administered twice daily, starting with $8 \mathrm{mg} / \mathrm{kg} /$ day from the day after transplantation, and it was subsequently adjusted according to serum cyclosporine levels. On the day of surgery, $500 \mathrm{mg}$ of methylprednisolone was administered. Successively, corticosteroid therapy consisted of $20 \mathrm{mg} /$ day of prednisone, reduced to $10 \mathrm{mg} /$ day at 1 month and to $5 \mathrm{mg} /$ day after 3 months. Aza ( $1.5 \mathrm{mg} / \mathrm{kg} /$ day) or MMF (1500 mg/day) doses were adjusted according to the patient's leukocyte count. Only 16 of 120 subjects assumed MMF instead of Aza as an immunosuppressant; three of the subjects started it from the day of surgery, whereas the other 13 changed to MMF after the first rejection episode. ARj treatment consisted of three boluses of methylprednisolone (0.5-1 g/dose).

Clinical outcome parameters. All patients were followed-up for at least 2 years after transplantation or until removal of the transplant. Graft function was monitored by studying serum creatinine levels and ARj occurrence. The latter was assessed by clinical symptoms and, in all but three cases, confirmed by needle core biopsy. Histological diagnosis of $\mathrm{CRj}$ was made in five cases. We moreover considered as graft failure, because of $\mathrm{CRj}$, the six cases in which serum creatinine levels were persistently higher than $4 \mathrm{mg} / \mathrm{dL}$ at several subsequent controls.

Graft failure or patient death due to infectious or cardiovascular causes was recorded in one FCXM-/ARj+ patient, one FCXM+/ $\mathrm{ARj}$ - patient, and four $\mathrm{FCXM}-/ \mathrm{ARj}$ - patients.

FCXM. Patients' sera were screened for the presence of DS-Abs with flow cytometry cross-match. Samples were collected before transplantation, at regular intervals during the first year after transplant (on days $7,14,30,60,90,120,150,180,270$, and 365), and each time clinical symptoms led us to suspect the occurrence of $\mathrm{ARj}$.

Donor lymphocytes were collected from lymph nodes or spleen fragments, cryopreserved by a $10 \%$ dimethyl sulfoxide solution, and stored in liquid nitrogen until used.

FCXM monitoring was performed using a three-color fluorescence technique (9). Briefly, $2.5 \times 10^{5}$ donor lymphocytes were incubated with $75 \mu \mathrm{l}$ of undiluted serum for $30 \mathrm{~min}$. at $25^{\circ} \mathrm{C}$. After two wash steps with phosphate-buffered saline solution that contained $5 \%$

TABLe 1. Pretransplant recipient characteristics

$\begin{array}{lc}\text { Age, mean } \pm \text { SD }(\mathrm{yr}) & 39.3 \pm 10.9 \\ \text { Gender }(\mathrm{M} / \mathrm{F}) & 74 / 46 \\ \text { Transplant no. } & \\ 1 & 116 \\ 2 & 4 \\ \text { Transfused patients }(\%) & 50 \\ \text { No. of transfusions/patient, mean } \pm \text { SD } & 3.6 \pm 3.3 \\ \text { HLA-AB mismatch, mean } \pm \text { SD } & 1.9 \pm 0.9 \\ \text { HLA-DR mismatch, mean } \pm \text { SD } & 0.6 \pm 0.6\end{array}$


TABLE 2. Posttransplant patient population characteristics ${ }^{a}$

ARj episodes

0

1

2

Time to first ARj

$<3$ months

$>3$ months

Graft failure

Arj

$\mathrm{CRj}$

Other

DS-Ab-positive patients

Time to DS-Ab appearance

$<3$ months

$>3$ months

Abbreviations used in table: $\mathrm{ARj}$, acute rejection; $\mathrm{CRj}$, chronic rejection; DS-Abs, donor-specific antibodies.

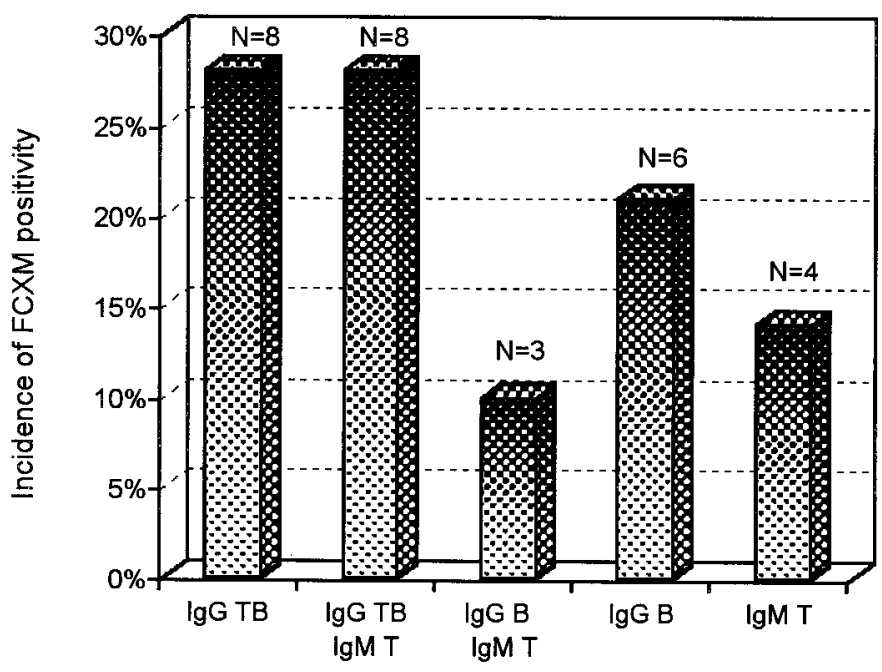

FIGURE 1. Analysis of FCXM positivity in relation to antibody specificity for donor $T$ and/or $B$ lymphocytes and the class of detected immunoglobulins.

fetal bovine serum and $0.1 \%$ sodium azide (PBS-Flow), $50 \mu \mathrm{l}$ of pretitred fluorescein isothiocyanate (FITC)-conjugated $\mathrm{F}\left(\mathrm{ab}^{\prime}\right)_{2}$ fragment of goat anti-human IgG or IgM (Dakopatts, Denmark), $5 \mu \mathrm{l}$ of peridinin chlorophyll protein-conjugated anti-CD3 monoclonal antibody $(\mathrm{mAb})$, and $5 \mu \mathrm{l}$ of phycoerythrin-conjugated anti-CD20 mAb were added to each tube. After a $30 \mathrm{~min}$. incubation at $4^{\circ} \mathrm{C}$ in the dark, the cells were washed twice with cold PBS-Flow and resuspended in $200 \mu \mathrm{l}$ PBS plus $1 \%$ paraformaldehyde until analysis. For all FCXMs, donor lymphocytes were incubated with the patient's test serum, a positive control serum (a pool of $>5$ patients' sera, each containing $>90 \%$ panel-reactive antibodies) and a negative control serum (a pool of $>5$ sera from healthy, nontransfused male subjects). Flow cytometric analysis was performed with a FACScan flow cytometer and Cell Quest software (Becton Dickinson, CA). Data were collected by logarithmic amplification, and fluorescence intensity was displayed on 1,024 channels. From each sample, 10,000 cells were captured in the lymphocyte gate, and analysis was performed on the fluorescence 1 (FL1) histogram (anti-human IgG or IgM) using gates on CD3- and CD20-positive cells. A positive cross-match was defined as a median channel shift of more than 2 SD above the predetermined median channel shift from the negative control.

To exclude false positives caused by the presence of auto-reactive antibodies, all positive samples were screened for the presence of such antibodies using the previously described technique.

FlowPRA. All sera that were IgG positive with the FCXM technique were investigated using the FlowPRA class I and II screening test (One Lambda, Inc., CA), which consists of a pool of microbeads coated with purified HLA class I or class II antigens from 30 cell lines covering all common HLA antigens. According to the manufacturer's suggested protocol, class I and II microbeads ( $5 \mu$ l of each type) were mixed with $20 \mu \mathrm{l}$ of sample serum. The mixture was then incubated for $30 \mathrm{~min}$. at $25^{\circ} \mathrm{C}$. After three washes, $100 \mu \mathrm{l}$ of properly diluted FITC-conjugated goat anti-human IgG $(\mathrm{Fc} \gamma)$ was added, and the samples were incubated again in the same conditions. The microbeads were then washed twice and resuspended in $0.5 \mathrm{ml}$ of fixing solution. Negative and positive control sera were tested in the same manner. From each test tube, 10,000 events were collected and a two-color analysis was performed using a FACScan flow cytometer and Cell Quest software. Two gates were set on the fluorescence 2 (FL2) histogram to analyze class I (FL2-negative particles) and class II (FL2 high-fluorescent particles) beads separately. The percentage of beads that had shifted to the right of the cut-off point set on the FL1 histogram of the negative control serum represented the amount of class I and/or II antibodies detected in each serum sample.

Statistical analysis. The $\chi^{2}$ test, Mann-Whitney two-sample test, and Student $t$ test were used for statistical comparison. $P<0.05$ was considered significant.

\section{RESULTS}

Patients' characteristics and renal allograft outcome. Posttransplant characteristics of the patients are listed in Table 2. Thirty subjects experienced at least one ARj episode, and six of them had two ARjs. Patients who suffered ARj were analyzed according to the early (within 3 months after transplantation) or late (after 3 months) onset of ARj; therefore, 25 of 30 subjects were classified as early onset and the other five as late onset.

Graft failure due to CRj occurred in 10 patients. Only one subject lost the graft because of severe ARj. Moreover, in four cases, failure was caused by severe viral and/or mycotic infections, and two patients died of acute myocardial ischemia.

FCXM results and graft outcome. Analysis of FCXM monitoring during the first posttransplant year showed that 29 (24.2\%) patients produced alloantibodies specific for $\mathrm{T}$ and/or $\mathrm{B}$ donor lymphocytes and that in 24 of them, DS-Abs made a precocious appearance, being detectable within the third month after transplantation. Data in Figure 1 shows that all but four FCXM-positive patients produced IgG DS-Abs, whereas the other four subjects (14\%) showed exclusive IgM FCXM positivity. As far as antibody target cells are concerned, we found that just six (21\%) of the 29 FCXM-positive

TABLE 3. ARj incidence, graft outcome, and serum creatinine levels ( 2 years after transplantation) according to FCXM status

\begin{tabular}{cccc}
\hline & $\begin{array}{c}\text { FCXM positive } \\
(\mathrm{N}=29)\end{array}$ & $\begin{array}{c}\text { FCXM negative } \\
(\mathrm{N}=91)\end{array}$ & Significance \\
\hline Acute rejection & & & \\
Positive & $18(62 \%)$ & $12(13 \%)$ & $P<0.00001$ \\
Negative & $11(38 \%)$ & $79(87 \%)$ & \\
Graft outcome & & & \\
Graft failure & $10(34 \%)$ & $1(1 \%)$ & $P<0.00001$ \\
Good function & $19(66 \%)$ & $90(99 \%)$ & \\
Serum creatinine & $2.46 \pm 1.27$ & $1.57 \pm 0.54$ & $P<0.0001$ \\
$(\mathrm{mg} / \mathrm{dL})^{a}$ & & & \\
\hline
\end{tabular}

${ }^{a}$ Data are given as mean $\pm \mathrm{SD}$. 
TABLE 4. 2-year graft outcome based on simultaneous analysis of FCXM and ARj data

\begin{tabular}{lcccc}
\hline & $\begin{array}{c}\text { FCXM+/ARj } \\
(\mathrm{n}=18)\end{array}$ & $\begin{array}{c}\text { FCXM-/ARj+ } \\
(\mathrm{n}=12)\end{array}$ & $\begin{array}{c}\text { FCXM+/ARj- } \\
(\mathrm{n}=11)\end{array}$ & $\begin{array}{c}\text { FCXM-/ARj- } \\
(\mathrm{n}=79)\end{array}$ \\
\hline Good function $^{a}$ & $55.6 \%$ & $91.7 \%$ & $81.8 \%$ & $100 \%$ \\
Graft failure $^{a}$ & $44.4 \%^{b}$ & $8.3 \%^{b}$ & $18.2 \%$ & $0 \%$ \\
\hline
\end{tabular}

${ }^{a}$ Considering only failures due to $\mathrm{ARj}$ or $\mathrm{CRj}$.

${ }^{b} P=0.043$.

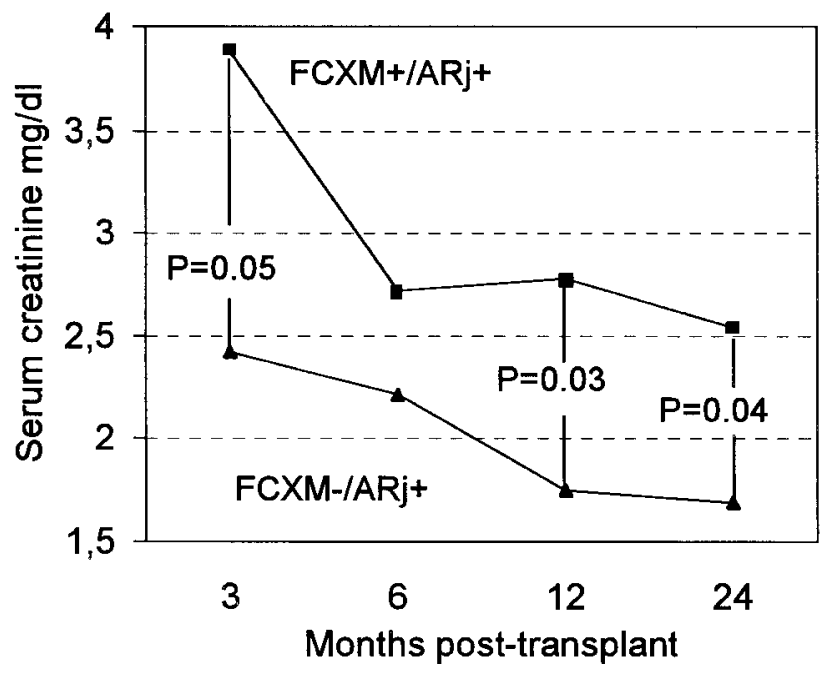

FIGURE 2. The importance of DS-Abs production expressed as FCXM positivity in graft function during our follow-up period in subjects with $\mathrm{ARj}$ episodes. Mean serum creatinine levels in FCXM-positive patients $(\square)$ appeared significantly higher than those of FCXM-negative ones $(\Delta)$ throughout the observation period.

patients showed IgG DS-Abs exclusively against donor B lymphocytes.

No correlation between the amount and type of FCXM positivity and graft outcome was established.

When we analyzed the length of FCXM positivity, four (16\%) subjects showed a persistent positivity throughout our observation and all of them suffered graft loss during the same period. Fifteen of the remaining 25 patients no longer presented serum DS-Abs after 1 month of observation, whereas in the other 10 patients, the disappearance of antibodies took place over a period of clinical monitoring that ranged from 1.5 to 9 months. As far as graft failure is concerned, no significant difference was observed between subjects showing antibody positivity for a short period and those presenting DS-Abs for a long time. This may be explained by the fact that DS-Abs, although still produced, may be bound to the graft or masked into immune complexes formed with soluble HLA antigens released from the graft cells.

The correlation between FCXM-monitoring results and clinical follow-up revealed a strong correlation between antibody production and graft function. In fact, a significantly higher incidence of both $\mathrm{ARj}$ and immunologically determined graft failure was observed in FCXM-positive patients compared with negative ones (ARj: $62 \%$ vs. $13 \%, P<0.00001$; $\mathrm{CRj}$ or removal of the graft: $34 \%$ vs. $1 \%, P<0.00001)$. This finding was moreover supported by serum creatinine levels with mean values of $2.46 \pm 1.27 \mathrm{mg} / \mathrm{dL}$ in FCXM-positive pa- tients and $1.57 \pm 0.54 \mathrm{mg} / \mathrm{dL}$ in the negative ones, 2 years after transplantation, thus resulting in a $P<0.0001$ (Table 3).

Noteworthy, in 9 of $18 \mathrm{FCXM}+/ \mathrm{ARj}+$ patients, DS-Abs appearance preceded any clinical manifestation of ARj by 10 to 1 days.

Further evidence of the clinical value of FCXM in evaluating graft function was obtained by dividing the patients into four groups according to FCXM-monitoring results and $\mathrm{ARj}$ occurrence (group 1: $\mathrm{FCXM}+/ \mathrm{ARj}+$; group 2: FCXM-/ $\mathrm{ARj}+$; group 3: FCXM+/ARj-; and group 4: FCXM-/ARj-) (Table 4). Our data highlighted a significantly higher incidence of graft failure in FCXM+/ARj+ patients than in subjects showing only ARj occurrence without DS-Abs production $(44.4 \%$ vs. $8.3 \%, P=0.043)$. A higher incidence of graft failure was, furthermore, ascertained in FCXM+/ARj- subjects $(18.2 \%)$ than in FCXM-/ARj+ subjects $(8.3 \%)$.

Renal function, evaluated $3,6,12$, and 24 months after transplantation, also appears to be more closely related to DS-Abs production than to ARj. In fact, $\mathrm{FCXM}+/ \mathrm{ARj}+$ patients have always shown higher mean serum creatinine levels than FCXM-/ARj+ ones (3 months: $3.9 \pm 2.6 \mathrm{mg} / \mathrm{dL}$ vs. $2.4 \pm 1 \mathrm{mg} / \mathrm{dL}, P=0.0499 ; 6$ months: $2.7 \pm 1.3 \mathrm{mg} / \mathrm{dL}$ vs. $2.2 \pm 0.8 \mathrm{mg} / \mathrm{dL}, P=$ n.s.; 12 months: $2.8 \pm 1.6 \mathrm{mg} / \mathrm{dL}$ vs. $1.8 \pm 0.5 \mathrm{mg} / \mathrm{dL}, P=0.0333$; and 24 months: $2.5 \pm 1.3 \mathrm{mg} / \mathrm{dL}$ vs. $1.7 \pm 0.5 \mathrm{mg} / \mathrm{dL}, P=0.0409$ ) (Fig. 2). Thus, 2 years after transplantation, FCXM-positive subjects had higher mean serum creatinine levels than FCXM-negative subjects, regardless of the occurrence of ARj (Fig. 3).

We also investigated the possible role of other covariables in graft loss among FCXM-positive subjects. No significant variations in donor/recipient age, weight, and posttransplant acute tubular necrosis were found between FCXM-positive and -negative patients. Delayed graft function had a higher incidence in FCXM-negative patients (29/91, 31.9\%) than in the FCXM-positive patients $(6 / 29,20.7 \%)$; thus, this variable
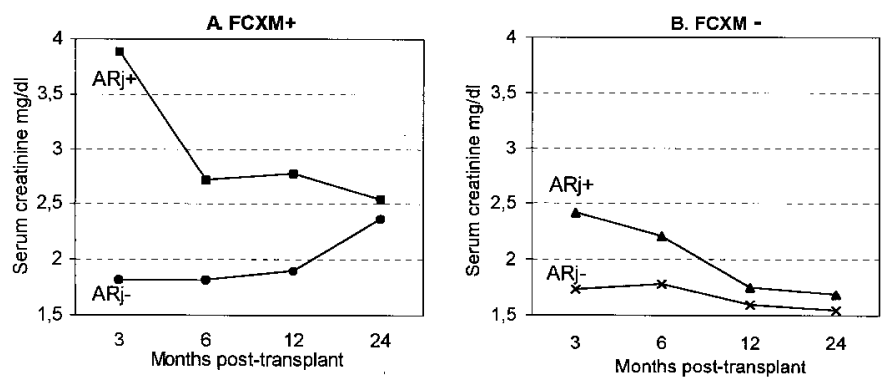

FIGURE 3. Comparison of mean serum creatinine levels in FCXM-positive and -negative patients according to ARj occurrence. In panel A (FCXM+ patients), a higher mean serum creatinine is apparent after 2 years, regardless of ARj occurrence, whereas in panel B (FCXM-), all patients are stable with low serum creatinine at the same period, notwithstanding ARj status. 
does not constitute a higher risk factor for graft loss in those patients who produce DS-Abs.

Immunosuppressant therapy with MMF was moreover considered. In fact, it has been widely demonstrated how this drug, which is a specific inhibitor of de novo purine synthesis, is able to inhibit T- and B-lymphocyte proliferation (20-21) and to reduce in vivo antibody formation in both animals and man (22-23). Even though only a small number of patients in our study population had been treated with MMF, it was nonetheless possible to observe that 7 of 19 (36.8\%) FCXMpositive patients, who had a good graft function 2 years after transplantation, had been treated with this immunosuppressant drug. On the contrary, all 10 FCXM-positive patients, who suffered graft loss, had received only standard therapy with Aza. The better clinical outcome registered in FCXMpositive patients treated with MMF may be due to its ability to block antibody production that in turn led to a stop in antibody-mediated damage of the transplanted organ.

FlowPRA analysis results and HLA matching. The FlowPRA class I and II screening test was performed in 20 of 25 FCXM-positive patients who produced IgG alloantibodies specifically directed against the donor's T and/or B lymphocytes. Anticlass I antibodies were found in seven (35\%) patients, whereas anticlass I and II DS-Abs were found in 11 $(55 \%)$ cases. Only two $(10 \%)$ subjects exclusively produced anticlass II antibodies. Therefore, $90 \%$ of the examined subjects produced antibodies specifically directed against the HLA class I antigens of the graft (Fig. 4). Evaluation of the patient sera with only anti-B lymphocyte IgG DS-Abs according to the FCXM analysis revealed an interesting pattern of anti-HLA antibody production: two $(33.3 \%)$ of six patients exclusively produced anticlass II antibodies, one (16.7\%) patient formed only anticlass I DS-Abs, and the remaining three $(50 \%)$ patients presented both anticlass I and II antibodies. The presence of anticlass I DS-Abs in patients who showed only anti-B lymphocyte antibody production according to FCXM analysis may be due to low-titre antibodies against class I antigens. In these cases, it is easier to identify such antibodies when they are bound to B lymphocytes,

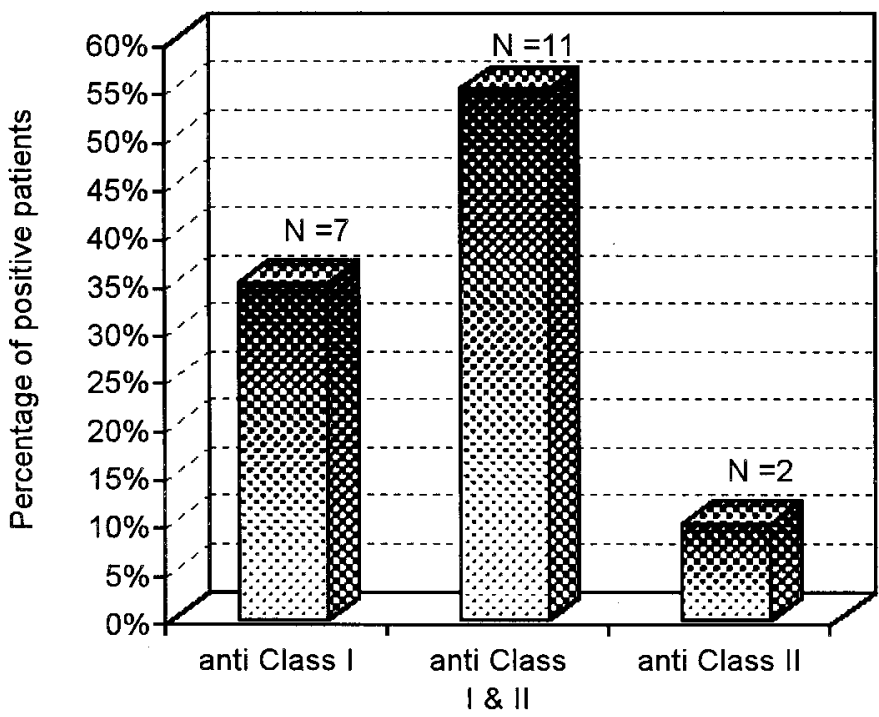

FIGURE 4. Percentages of anticlass I and/or anticlass II antibody-positive patients among IgG FCXM-positive ones. which constitutionally express a higher number of HLA class I antigens than $\mathrm{T}$ lymphocytes.

When we analyzed HLA-A, HLA-B, and HLA-DR mismatches in relation to anti-HLA class I and II antibodies, a significant incidence of B-locus mismatches was found in anti-HLA class I-positive patients when compared to negative patients ( $1.23 \pm 0.66$ vs. $0.92 \pm 0.59, P=0.0248)$ (Fig. 5). No evidence of a correlation between DR mismatches and the presence of anticlass II DS-Abs was found.

\section{DISCUSSION}

FCXM is undoubtedly a sensitive technique for identifying alloantibodies in renal-transplanted patients. With this technique, we evaluated 120 cadaveric kidney-transplanted patients for DS-Abs production to ascertain the relevance of the donor-specific humoral immune response on renal graft outcome. It is important to emphasize that all patients included in our study did not present with preformed antibodies against donor HLA-mismatched antigens according to both cytotoxic or flow cytometric analyses. Therefore, ARj or CRj episodes that occurred in our study population did not depend on a possible history of presensitization.

Recent findings suggest that posttransplant production of Ds-Abs is strongly associated with $\operatorname{ARj}(15-17,24)$. Our data are consistent with this theory, because $62 \%$ of FCXM-positive patients suffered ARj episodes compared to only $13 \%$ of the FCXM-negative patients $(P<0.00001)$. FCXM monitoring revealed the onset of a humoral immune response towards the graft before the appearance of any clinical evidence of rejection in $50 \%$ of $\mathrm{FCXM}+/ \mathrm{ARj}+$ patients, making this procedure an essential tool for an earlier detection of ARj occurrence, as also stated by Scornick et al. (15), Utzig et al. (17), and Daniel et al. (25). On the other hand, our analysis did not confirm a correlation between the type and degree of FCXM positivity and the occurrence of ARj episodes as shown by these same authors.

Further evidence of the strong correlation between FCXM positivity and graft outcome can be seen by comparing serum

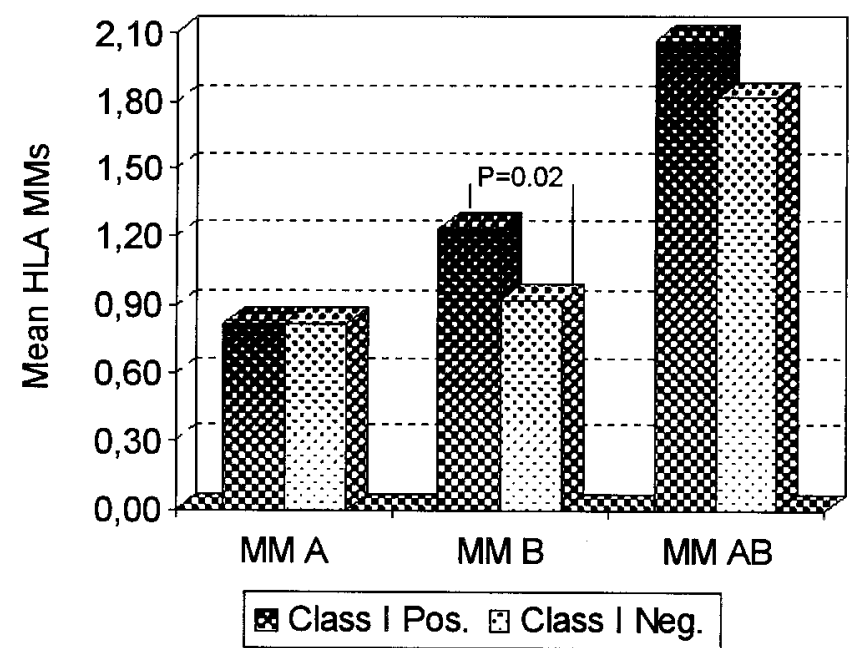

FIGURE 5. Analysis of mean HLA mismatches (MMs) in antiHLA class I-positive and -negative patients. It is worth noting that patients who produced class I antibodies showed a prevalence of B-locus mismatches compared with anticlass I-negative patients $(P=0.02)$. 
creatinine levels and graft function with FCXM status. In fact, FCXM-positive patients constantly showed significantly higher values of serum creatinine throughout our observation period when compared with negative patients.

The production of DS-Abs appears even more important in determining graft failure because of 11 cases of graft loss for $\mathrm{ARj}$ or $\mathrm{CRj}, 91 \%$ were among FCXM-positive subjects whereas only 9\% occurred in FCXM-negative subjects $(P<0.00001)$. It is worth noting that 2 of 10 FCXM-positive subjects who lost the graft during our observation period did not show any evidence of ARj but suffered only a progressive deterioration of renal function, which eventually led to the complete failure of the graft. DS-Abs may, therefore, be considered one of the main causes of $\mathrm{CRj}$, as also stated by Abe et al. (18) and Kirby et al. (26). Our findings do not, however, confirm those reported by other authors. Abe et al. (18) assessed the ineffectiveness of Ds-Abs that appeared within the first month after transplantation in influencing graft survival. Our data do not favor this hypothesis because 4 of 10 FCXM-positive patients who suffered graft loss showed a humoral response within the first month. The other controversial issue is represented by the fact that our data did not confirm a stronger association between anti-B lymphocyte antibodies and $\mathrm{CRj}$, as proposed by the above mentioned authors, because only 3 of 10 FCXM-positive subjects who experienced graft failure demonstrated exclusive anti-B lymphocyte IgG antibody production.

As far as the persistence of FCXM positivity is concerned, only four patients unremittingly produced DS-Abs throughout our observation period and all these subjects lost the graft; the other 25 patients showed FCXM positivity for a limited period of time, ranging from 1 to 10 months. Such events may be explained by either the appearance of antiidiotypic antibodies (27) or by the presence of graft-releasedsoluble HLA antigens that mask (28) or block DS-Abs in peripheral blood and bind them into immune complexes.

Acute vascular rejection, which is an antibody-mediated event, has been shown to influence graft survival in contrast to acute interstitial rejection (29). To assess the roles of ARj episodes and antibody formation on graft function, we comparatively evaluated the influence of these parameters on graft outcome. FCXM-positive patients who also suffered rejection episodes had a markedly worse outcome than patients whose clinical history was only positive for ARj occurrence. On the other hand, when considering the two parameters individually, FCXM positivity has been shown to be a much worse prognostic factor than ARj occurrence alone; in fact, our data showed that approximately one third (34\%) of FCXM-positive subjects lost the graft within 2 years from transplantation compared to only $1 \%$ among those who were negative for DS-Abs production $(P<0.00001)$. These results lead us to suspect that subclinical antibody-mediated vascular rejection might effectively cause long-term graft loss, even in the absence of clinical symptoms. All of these findings seem to indicate that FCXM positivity, that is to say DS-Abs production, may really represent a more important risk factor than $\mathrm{ARj}$ in determining $\mathrm{CRj}$ occurrence and, therefore, graft loss.

Further proof of the predominant role of antibody-mediated damage on renal transplant outcome can be gathered by evaluating its impact on serum creatinine levels. FCXM- and ARj-positive patients showed a mean value of $2.5 \mathrm{mg} / \mathrm{dL} 2$ years after transplantation, whereas FCXM-negative subjects were stable at $1.7 \mathrm{mg} / \mathrm{dL}(\mathrm{FCXM}-/ \mathrm{ARj}+$ group) or less (FCXM-/ARj- subjects) during the same period of clinical monitoring. However, the most interesting evidence comes from the FCXM +/ARj- group who showed, during the first posttransplant year, creatinine levels similar to those of FCXM-negative patients but with a subsequent steep rise at the end of the second year, leading to the same levels observed in the FCXM+/ARj+ group. Thus, renal function definitely appears to be more strongly related to DS-Abs production than to ARj occurrence.

Recent data have clearly highlighted the negative influence of anticlass I antibody production on renal graft survival. These antibodies are in fact held responsible for the loss of successive regrafts bearing previously mismatched HLA class I antigens (30). On this basis, we retrospectively analyzed the sera of all IgG-positive patients using class I and class II FlowPRA screening tests to highlight the HLA specificity of the DS-Abs revealed with FCXM analysis. Our results revealed the presence of anticlass I antibodies in a higher percentage $(90 \%)$ than those reported in literature (31), whereas the presence of anticlass II antibodies alone was observed in a very low percentage (10\%) of our subjects.

To investigate the relevance of HLA class I and class II mismatches on antibody production, we analyzed the incidence of HLA-A, HLA-B, HLA-AB, and HLA-DR mismatches in the anti-HLA-positive group of patients and among the anti-HLA-negative patients. No significant variation of mean HLA mismatches was observed when anticlass II antibody production was considered. On the contrary, we noted a strong link between the presence of anticlass I antibodies and B-locus mismatches $(P=0.0248)$, notwithstanding the standard matching priority of HLA-DR, HLA-B, and HLA-A. The finding of a high incidence of HLA-B mismatches among anticlass I DS-Abs-positive patients supports the data that concerns the harmful effect of these HLA mismatches on long-term graft survival.

In conclusion, we believe FCXM to be an essential tool in monitoring the onset of an immune response toward renal graft, because early detection of antibody production may be useful in identifying those patients who need a kidney biopsy and in developing appropriate immunosuppressive protocols. In this study, FCXM had a sensitivity of 90.9 and a specificity of 83.3 for $\mathrm{CRj}$ and graft failure; thus, the presence of DS-Abs detected by means of flow cytometric techniques constitutes a negative prognostic event and an independent risk factor for medium- and long-term graft survival.

\section{REFERENCES}

1. European Multicenter Trial Group. Cyclosporin in cadaveric renal transplantation: one-year follow-up of a multicenter trial. Lancet $1983 ; 11$ : 986.

2. Cecka JM, Terasaki PI. The UNOS scientific renal transplant registry. In: Terasaki PI, ed. Clinical Transplants. Los Angeles: UCLA Tissue Typing Laboratory, 1995; 1.

3. Tesi RJ, Henry ML, Eckhammas EA, Ferguson RM. Predictors of longterm primary cadaveric renal transplant survival. Clin Transplant 1993; 7: 345

4. Oluwole SF, Tezuka K, Wastie T, Stegall MD, Reestsma K, Hardy MA Humoral immunity in allograft rejection. Transplantation 1989; 48: 751.

5. Lobo PI, Spencer CE, Stevensson WC, Pruett TL. Evidence demonstrating poor kidney graft survival when acute rejections are associated with IgG donor-specific lymphocytotoxin. Transplantation 1995; 59: 357. 
6. Garavoy MR, Rheinschmidt MA, Bigos M, et al. Flow cytometry analysis: a high technology crossmatch technique facilitating transplantation. Transplant Proc 1983; 15: 1939.

7. Chapman JR, Deierhoi MH, Carter NP, Ting A, Monis PJ. Analysis of flow cytometry and cytotoxicity crossmatches in renal transplantation. Transplant Proc 1985; 17(6): 2480.

8. Cook DJ, Terasaki PI, Iwaki Y, Terashita GY, Lau M. An approach to reducing early kidney transplant failure by flow cytometry crossmatching. Clin Transplant 1987; 1: 253.

9. Bray RA. Flow Cytometry Crossmatching for solid Organ Transplantation. Methods Cell Biol 1994; 41: 103.

10. Pei R, Wang G, Tarsitani C, et al. Simultaneous HLA Class I and Class II antibodies screening with flow cytometry. Hum Immunol 1998; 59: 313.

11. Mahoney RJ, Ault KA Given SR, et al. The flow cytometric crossmatch and early renal transplant loss. Transplantation 1990; 49: 527.

12. Ogura K, Terasaki PI, Johnson C, et al. The significance of a positive flow cytometry crossmatch test in primary kidney transplantation. Transplantation 1993; 56: 294.

13. Mahoney RJ, Norman DJ, Colombe BW, Garavoy MR, Lecber DA. Identification of high and low risk second kidney grafts. Transplantation 1996; 61: 1349 .

14. Berteli AJ, Daniel U, Möhring K, Stachler G, Opelz G. Association of kidney graft failure with a positive flow cytometric crossmatch. Clin Transplant 1992; 6: 31 .

15. Scornik J, Salomon D, Lim P, Howard R, Pfaff W. Posttransplant donor antibodies and graft rejection: evaluation by two-colour flow cytometry. Transplantation 1989; 47: 287.

16. O’Malley KJ, Cook DJ, Roeskel L, et al. Acute rejection and flow cytometry crossmatch. Transplant Proc 1999; 31: 1216.

17. Utzig MJ, Blümke M, Wolff-Vorberck G, Lang H, Kirste G. Flow cytometry cross-match. A method for predicting graft rejection. Transplantation 1997; 63: 551.

18. Abe M, Kawai T, Futatsujama K, et al. Post operative production of anti-donor antibody and chronic rejection in renal transplantation. Transplantation 1997; 63: 1616.

19. Christiaans MHL, Overhof-de Roos R, Nieman F, van Hoof JP, van den Berg-Loonen EM. Donor-specific antibodies after transplantation by flow cytometry. Transplantation 1998; 65: 427.

20. Allison AC, Almquist SJ, Muller CD, Eugui EM. In vitro immunosuppres- sive effects of mycophenolic acid and an ester prodrugs, RS-61443. Transplant Proc 1991; 23(suppl 2): 10

21. Grailer A, Nichols J, Hullett D, Sollinger HW, Burlingham WJ. Inhibition of human B cell responses in vitro by RS-61443, cyclosporine A and DAB486 Il-2. Transplant Proc 1991; 23(1): 314.

22. Figueroa J, Fuad SA, Kunjummen BD, Platt JL, Bach FH. Suppression of synthesis of natural antibodies by mycophenolate mofetil (RS-61443) its potential use in discordant xenografting. Transplantation 1993; 55(6): 1371.

23. Kimball JA, Pescovitz MD, Book BK, Norman DJ. Reduced human IgG anti-ATGAM antibody formation in rebal transplant recipients receiving Mycophenolate Mofetil. Transplantation 1995; 60: 1379.

24. Valeri M, Piazza A, Torlone N, et al. HLA-DR matching and anti-donorspecific antibodies in kidney transplant recipients. Transplant Proc 1992; 24: 2514.

25. Daniel V, Berteli AJ, Röhl L, Pomer S, Opelz G. Non-complement-fixing antibodies as indicators for impending renal allograft rejection. Transplant Proc 1989; 21: 702.

26. Kirby JA, Givan AL, Shenton BK, et al. Renal allograft rejection: possible involvement of antibody dependent cell-mediated cytotoxicity. Transplantation 1990; 50: 225.

27. Suciu-Foca N, Reed E, D'Agati VD, et al. Soluble HLA antigens, anti-HLA antibodies, and anti-idiotypic antibodies in the circulation of renal transplant recipients. Transplantation 1991; 51: 593.

28. Piazza A, Torlone N, Valeri M, et al. Antidonor-HLA antibodies and soluble HLA antigens after kidney transplant. Transplant Proc 1993; 25: 3279 .

29. Van Saase JLCM, Van der Woude FJ, Thorogood J, et al. The relationship between acute vascular and interstitial renal allograft rejection and subsequent chronic rejection. Transplantation 1995; 59: 1280

30. Welsh KI, Van Dam M, Bewick ME, et al. Successful transplantation of kidneys bearing previously mismatched HLA A and B locus antigens. Transpl Int 1988; 1: 190.

31. Harmer AW, Heads AJ, Vaughan RW. Detection of HLA class I- and class II-specific antibodies by flow cytometry and PRA-STAT screening in renal transplant recipients. Transplantation 1997; 63: 1828.

Received 14 February 2000.

Accepted 12 September 2000. 